
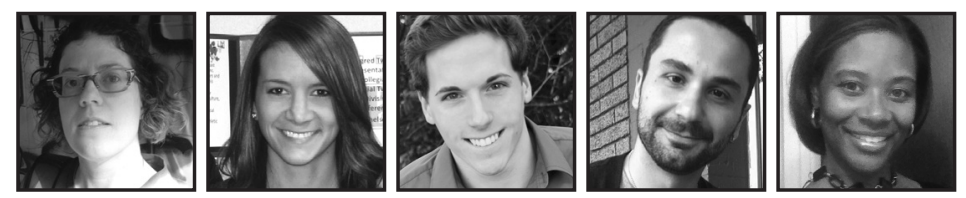

\title{
Using Arts-Based Research Exercises to Foster Reflexivity in Qualitative Research
}

\author{
Sandra L. Faulkner, Chelsea A. Kaunert, Yannick Kluch, Esen Saygin Koc, \\ and Stormy P. Trotter, Bowling Green State University
}

\section{ABSTRACT}

Reflexivity is a ubiquitous, varied, and, at times, contentious concept in qualitative inquiry that presents challenges as we strive to understand and use the concept in our work. The authors present their collaborative understanding of reflexivity using their semester-long research journals, reflexivity models, collaborative poetry, and collage exercises as evidence. The article details how using arts-based research exercises in the classroom can facilitate understanding and use of the concept of reflexivity.

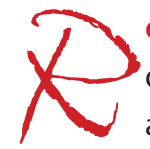
eflexivity is a ubiquitous, varied, and, at times, contentious concept in qualitative inquiry that presents challenges as we strive to understand and use the concept in our work. Lindlof and Taylor (2011) have described reflexivity as the "heartbeat of qualitative research" (p. 72), but questions about conceptualizations and usage of the concept arise when we talk about reflexivity in the classroom and in our qualitative work: What does reflexivity mean? How does one demonstrate reflexive understanding? Which position on reflexivity should we adopt as qualitative researchers? How do we teach reflexivity? These questions reflect the diverse understandings of reflexivity in qualitative methodology, and how "this diversity has created a sense of openness for doing ethnographic research...in turn, this openness has rendered reflexivity a contested intellectual phenomenon that is often characterized by contrasting and differing perspectives" (Berry \& Clair, 2011, p. 95). 
In order to unravel the complexity of the concept of reflexivity, we share the experiences of students ${ }^{1}$ enrolled in a qualitative research methods class in media and communication at a medium-sized midwestern university during the 2014 spring and the 2015 summer semesters. We detail how a semester-long investigation into reflexivity contributed to class understanding of the concept, the use of the concept in qualitative research, and how $A B R$ exercises can be used to improve teaching practices. We suggest that the use of arts-based research exercises facilitates the understanding and doing of reflexive qualitative research.

\section{Defining Reflexivity}

Like many concepts in qualitative research, the concept of reflexivity cannot easily be defined in a few words. For qualitative researchers, reflexivity has been conceptualized as a process that enriches the dialogue between the subject matter and the researcher (Calafell, 2013). As such, reflexivity means being aware of and acknowledging the researcher's contribution to the construction of meanings throughout the research process. It means acknowledging the impossibility of remaining outside of one's subject matter. At the heart of the concept of reflexivity, then, the researcher is viewed as an instrument of the research process. Thus, the researcher needs to acknowledge how he/she incorporates into his/her work a certain set of preconceived behaviors, attitudes, and beliefs, and in fact, we argue that these personal experiences enrich the research endeavor.

The idea of reflexivity challenges the view of knowledge production as independent of the researcher producing the knowledge and of knowledge as an objective entity (Berger, 2015). The researcher is therefore not only engaged with the process, but also a critical part of that process. In order to ensure quality in qualitative research, reflexivity needs to occur on all stages of the research process. Berger (2015) noted that being reflexive as a qualitative researcher "means turning of the researcher lens back onto oneself to recognize and take responsibility for one's own situatedness within the research" (p. 220). It is important to analyze the effect that our situatedness has on the subjects we study, the questions we ask, as well as the data we collect and interpret (Berger, 2015). Reflexivity is thus considered essential, potentially facilitating understanding of both phenomenon under study and the research process itself (Watt, 2007). 
Reflexivity represents an important tool for establishing trustworthiness in qualitative research, because "[i]f we do not consider the ways in which who we are may get in the way of portraying the voice of the participant, we may miss important meanings that are being presented by our participants" (Lietz, Langer, \& Furman, 2006, p. $x)$. Reflexivity allows researchers to increase the credibility of their work by detailing how their values, beliefs, knowledge, and biases influence this work (Cutcliffe, 2003). Further, Guillemin and Gillam (2004) argue that active engagement with reflexivity not only demonstrates rigor, but also helps ensure that our research practices are ethical. They argue that, "being reflexive in an ethical sense means acknowledging and being sensitized to the microethical dimensions of research practice and in doing so, being alert to and prepared for ways of dealing with the ethical tensions that arise" (p. 278).

\section{Applying Reflexivity}

Employing reflexivity within the classroom has the potential to make the classroom a less secret, dangerous place (Warren, 2011). Thus, we outline arts-based research activities that encourage students to strengthen their use of reflexivity as beginning qualitative researchers. Students during the 2014 spring semester engaged in two arts-based research exercises (reflexivity modeling and collage poetry) based on their semester-long reflexivity journals, and students during the 2015 summer semester engaged in three arts-based research exercises (reflexivity model, collage poetry, and exquisite corpse) and online discussions about reflexivity in order to deepen their understanding and knowledge of the concept. The journal served as inspiration and documentation of emerging definitions of reflexivity and demonstrated understanding of reflexivity as a process (Berry, 2013; Faulkner, 2016). We present the journal exercise and the arts-based research model, collage, and exquisite corpse exercises before presenting our different understandings of reflexivity that emerged. Our goals with this documentation are to offer others a way to process their own reflexivity and play with the tensions between definitions, practice, and knowledge of reflexivity within the classroom.

\section{Reflexivity Journal Exercise}

At the beginning of the semester, the course instructor asked students to keep a reflexivity journal wherein they recorded their reflections on research exercises and activities that we conducted in and outside of class given that reflexivity is a process that enriches the dialogue between the subject matter and the researcher (Calafell, 2013). 
The point of the journal was for students to document their evolving sense of reflexivity as it related to them as researchers, their research, and how reflexivity is included and excluded in the research process. Through the journaling exercise, students began to create and explore their own internal dialogues. The students took notes on readings, answered reflection questions about in-class activities, and used the journal to develop a paper and/or performance that would be included in the final class presentation. This journal exercise was a way to anchor reflexivity in students' daily scholarly lives. Students re-created what they were experiencing within the classroom and were able to reflect on the implications of such experiences. The journal was also used as material for the arts-based research exercises we present now.

\section{Reflexivity Model Exercise}

After nine weeks of keeping a reflexivity journal, students answered the following questions based on Keith Berry's (2103) conceptualization of reflexivity as spinning: (1) What is reflexivity? What conceptualization works best for you and why?; (2) How is reflexivity important for qualitative work, and your work in particular?; (3) What is spinning reflexivity?; and (4) How will you incorporate your understanding of reflexivity into your work? The students then considered their answers when the instructor asked them to draw a model of reflexivity during class time using newsprint and markers; they were to define reflexivity through a model, words, and/or an image. See Figure 1 for an example of what students produced. The instructor took digital photos of all of the reflexivity posters and posted them in the on-line course management system for students to reference.

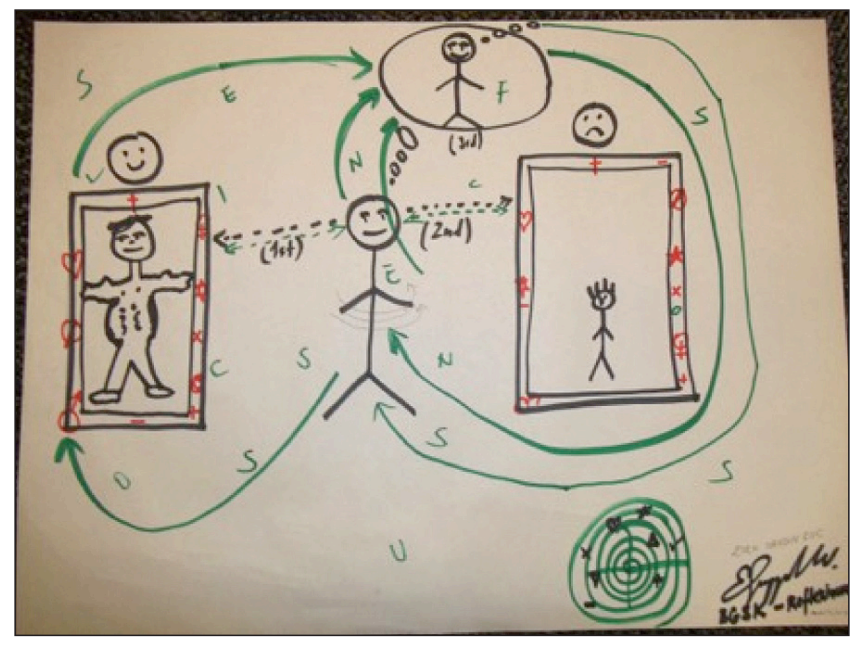

Fig. 1: Reflexivity model poster 


\section{Collage Exercise}

In the class period following the reflexivity model exercise, students created their own reflexivity collages. The instructor asked them to bring their reflexivity journals and consider the reflexivity models they had created to present an interview or interviews from their class homework as a collage poem (see Figure 2).

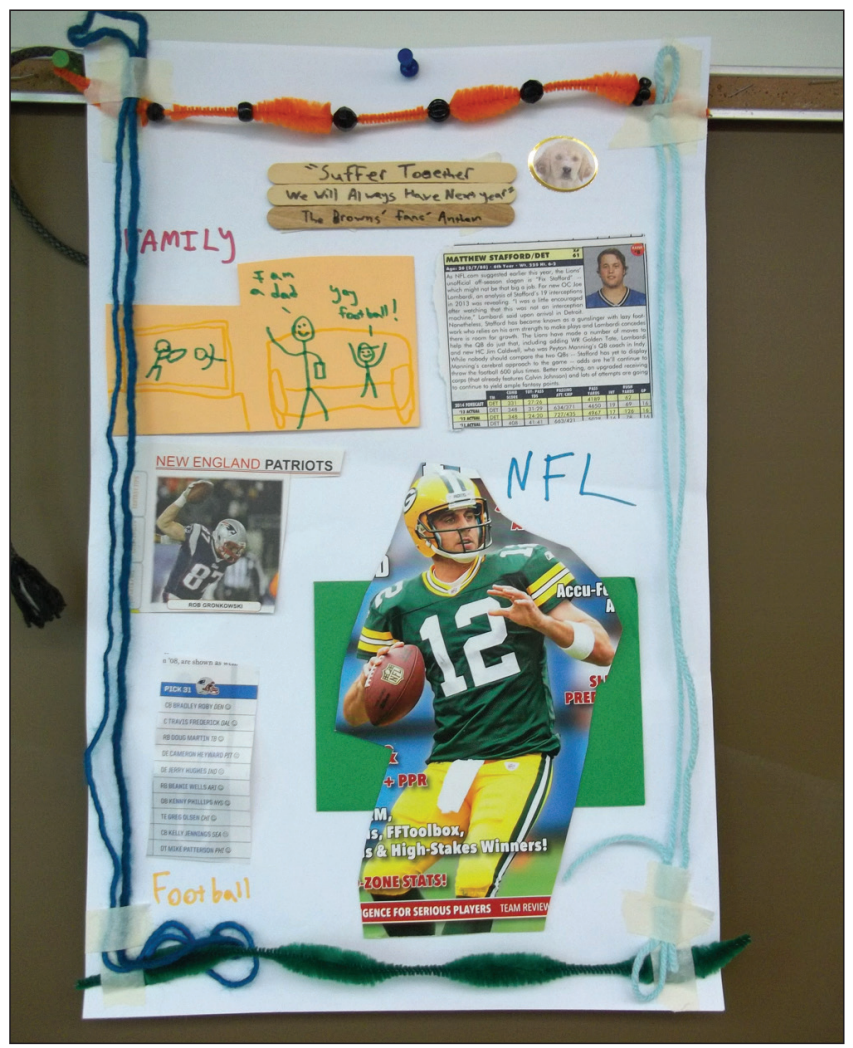

Fig. 2: Reflexivity interview collage

As an alternative, students could present the self as a researcher showing their understanding of how their positionality influences their research (see Figures 3 and 4). The instructor provided students the collage poem exercise from her poetry book (Faulkner, 2014), which encouraged them to use interview transcripts, photos, field notes, letters, email, texts, their researcher journal, research memos, crayons, pencils, pens, paint, double-sided tape, glue, yarn, magazines, cardboard, metals, fibers, and recycled objects. 


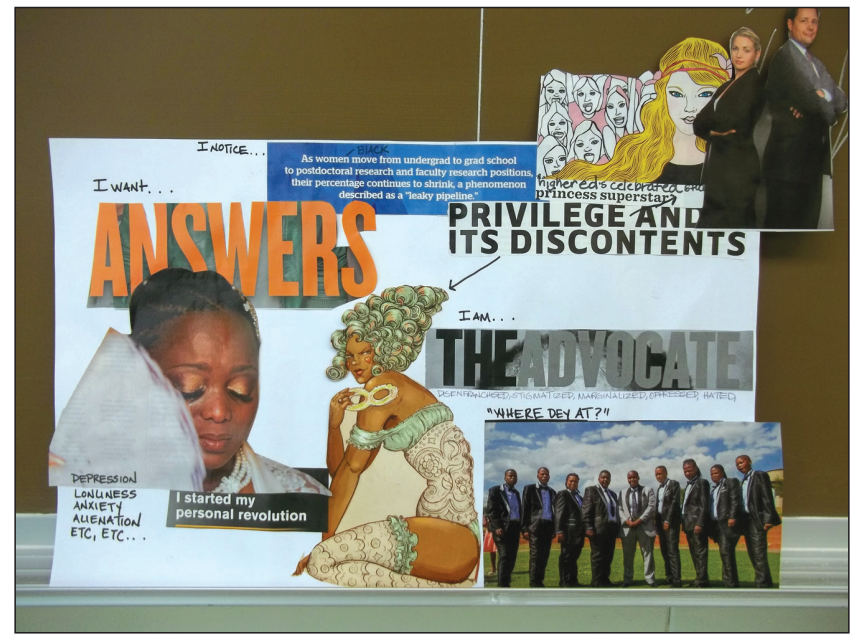

Fig. 3: Researcher reflexivity collage

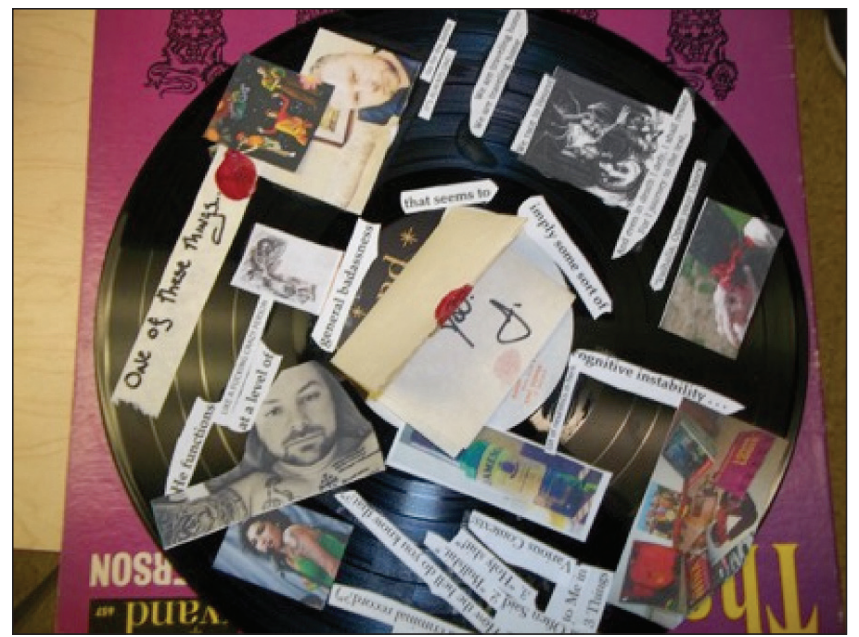

Fig. 4: Researcher reflexivity collage

In addition, the students had the option to create their collages on-line, such as on a personal website or blog (see Figure 5). Since this was done during class time, students were able to share the processes behind their reflexive collages. Reflexivity is not done alone; instead it is a way to engage the classroom together in a powerful way (Warren, 2011). 


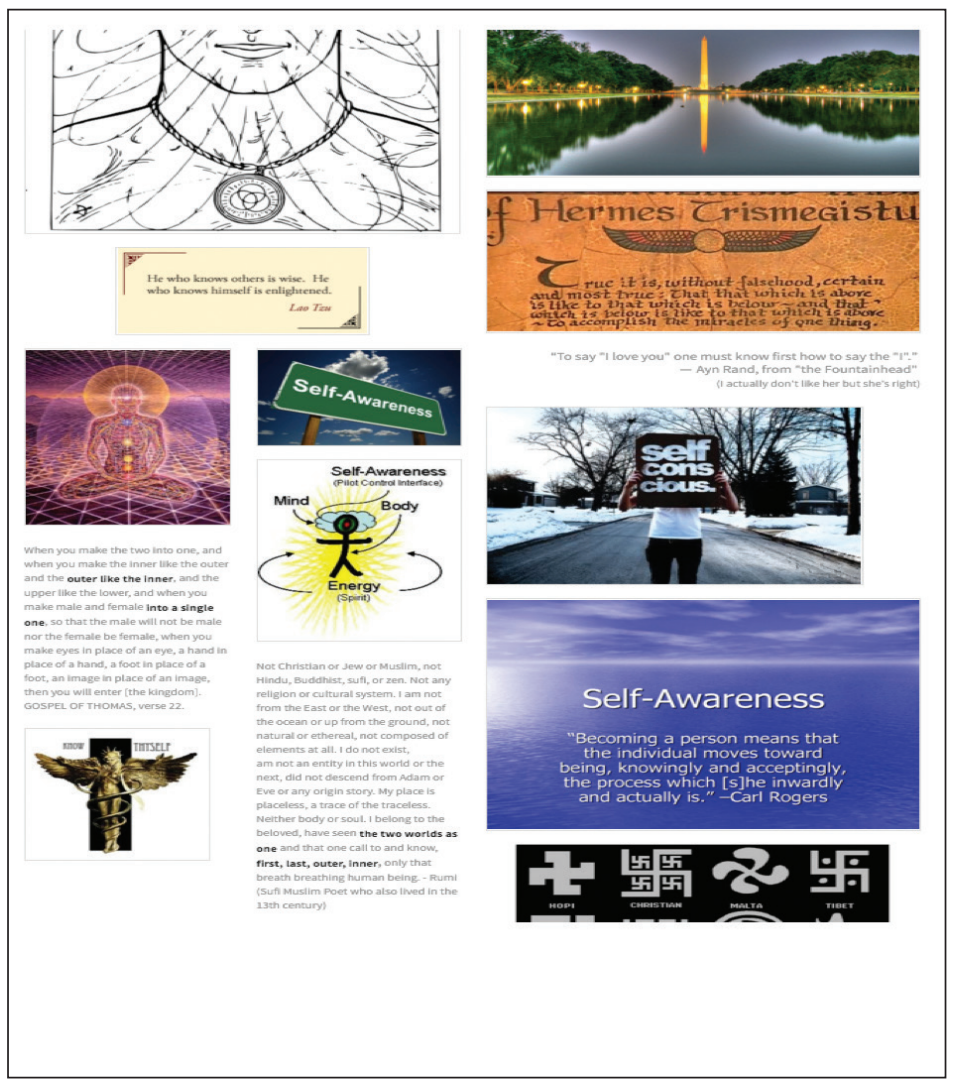

Fig. 5: Reflexivity blog

\section{Exquisite Corpse Exercise}

The students in the 2015 summer session played the surreal parlor game Exquisite Corpse as a means to tap into their collective thinking about reflexivity from our semester-long discussions and exercises. The game is a collaborative poetry writing exercise meant to help us get unstuck from our usual ways of thought and provide a way to connect to larger cultural issues (e.g., http://www.poets.org/poetsorg/ text/play-exquisite-corpse). This parlor game was first described by the French surrealist André Breton in 1948, who posited that these types of practices were not only entertaining, but also provided a necessary antidote to the miserable imitations of so-called physical reality (Ellenwood, 2005). Exquisite Corpse is a useful teaching exercise for liberating individuals' creativity and, perhaps more importantly, an exercise that shifts the focus from the final product to the actual process that goes into creating 
the product. The focus on process in Exquisite Corpse mirrors the focus on iterative process in qualitative research. Many qualitative scholars acknowledge the importance of process and the emergent design is qualitative research (see Creswell, 2007; Denzin \& Lincoln, 2000; Ragin, 1987; Tracy, 2013). Thus, Exquisite Corpse allows students to practice spontaneity, to go beyond conventional methods, and to be more open to uncertainty.

The typical rule is that each person who plays will not see what the other has written in order to allow for creativity and surprise. Other rules can be made about the form, topic, length, and editing of the poem. During class, each student began a poem about reflexivity to circulate around the room. We ended up with seven poems, and we present the three best exquisite corpse poems created:

\section{Reflexivity}

It is the product of our past experiences that we have internalized. Reflexivity helps us interpret those experiences. It allows us to acknowledge how these past experiences affect the research of the present. Yet it involved looking at those experiences with a fresh \& new perspective.

Involves admitting that everyone is a dynamic being comprised of UNSTABLE

\section{Energy}

Constant learning and relearning. It is important to examine the effect that our situatedness has on our subjects.

\section{Reflexivity...}

is an internal dialogue

It is also an external dialogue-

a dialogue with the literature and culture around you.

Reflexivity is digging for answers.

It is an integral part of research

itself.

How we create meaning from data

allows for us to determine how meaning is fabricated within a certain culture 
or society

It is the story we create when we close

our eyes and listen to our heart.

\section{Reflexivity Two}

When you step out of your own skin

to find out what is crawling

under your skin.

Taking a deep breath and truly focusing

inward.

In order to ensure quality in qualitative research

adding that voice that the silent yearn

to hear.

It is a rigorous journey inside

the self.

It is making your inside known

to the outside - that is to the

scholarly community.

It also involves a

conscious effort on 'filtering' as

we try \& understand other

perspectives.

\section{Reflections on Reflexivity}

When students completed the arts-based exercises, they answered reflection questions about each project. The instructor noted that the use of arts-based exercises, in combination with a journal and online discussion, produced the most nuanced wrestling with understandings she has seen in methods classes. The students' articulations demonstrated the continual process of defining reflexivity based on history, identities, relationships, and positionalities (Berry, 2013), and the impossibility of one answer to the question, what is reflexivity? Students discussed and presented reflexivity as recognizing privilege, as dialogue, as practice, as poetic, as analysis of identities, and as query. As such, these activities illustrate how reflexivity is a practice of mindfulness as students recognize their own identities and standpoints (Berry, 2013). We present examples of the reflections on reflexivity in Table 1. 
Table 1

Reflexivity As...

\section{RECOGNIZING PRIVILEGE}

- I was thinking that positioning yourself and recognizing privilege would add to your studies. And, in some situations we are all disadvantaged (I'm thinking of this as a dialectic).

- Reflexivity itself is not always good. Some researchers question the assumptions and dark side of reflexivity: "Some forms of reflexivity are reproductive, repetitious and reinforce existing power relations, while others may be challenging and disruptive" (Fox \& Allana, 2014, p. 367). The consequence of reflexivity depends on how we approach this reflexive exercise.

Reflexivity actually helps to constitute these structures and contributes to inequalities by its habitual representation of them: such analyses may be greatly underestimating the ways in which reflexivity is part of everyday habit and hence overestimating the possibilities of gender detraditionalization. (p. 34)

We should be wary of whether we only present our own voice and neglect others during the reflexive process. We always need to keep in mind the goal of reflexivity to counter the dark side of reflexivity.

\section{DIALOGUE}

- I definitely agree that reflexivity is "not a single or universal entity but a process - an active, ongoing process that saturates every stage of the research" (Guillemin \& Gillam, 2004, p. 274). I also like the idea of reflexivity as being dialogue with others and the literature. However, I want to add that it is also internal dialogue. Reflexivity includes dialogue with the self in order to scrutinize one's own biases in the research.

- I would interpret Berry's definition of spinning reflexivity as a process of exploring who you are and what you stand for in relation to your world. Such journeys can be exciting and wonderful and others can be extraordinarily painful. A good ethnographer will approach the study with compassion and be aware of the trust and respect that is needed to validate the subject's(s') reality.

- Can one be aware of his/her relationships without being aware of him/herself? When we look in the mirror, what we see is our face and our body. However, if you look at someone else that you know in the mirror, you will realize that the mirror is showing that person in a reflective way, but everything is the other way around. What we need is another mirror! We can't only see ourselves looking in the mirror; we also look into the reflection of our reflection in the second mirror. We need to look on both of them. We look to keep looking, shifting from one to another, and looking at ourselves without a mirror. 


\section{PRACTICE}

- Reflexivity is the notion that we are always present in our work and that it is difficult to separate ourselves from our own knowledge and experience. It is also the process of engaging in and interpreting the works of others as we attempt our own research. The idea that reflexivity is an evolution is how I best see the concept. It is a continuous cycle of research in which we acknowledge ourselves and the thoughts of others into our work. This integration allows us to think deeper and look further into questions that we might answer with our own research.

- I'm going to draw upon "Reflexivity" using the class activity, where a model was drawn to show how we interpret reflexivity in the realities of our life. I understand that we all look at the world around us with a certain frame of lens, which is subconsciously ingrained in us at a very young age. Thus, sometimes we fail to imbibe or borrow from the ideas of different lenses. When we move away from the "typical" frame of mindset and approach the world with a fresh perspective, we have engaged in some reflection, where we don't always stay adamant to one particular understanding and are willing to be more flexible and integrative.

- Reflexivity is the continual analyzing of what the preconceptions of the researcher are based on: the research and the researcher's personal belief system. Knowledge is produced based on this circular analytical process. The researcher's assumptions or preconceptions may have an effect on decisions related to the research. Reflexivity allows for us to determine how meaning is fabricated within a certain culture or society.

\section{POETIC}

- Reflexivity is poetry, an intentional and artistic act that requires a naked intimacy and a level of honesty into which one cannot merely step. It must be nurtured. I see it as a circle of mirrors surrounding me, and as I write upon one mirror, my words are reflected back and forth, across and around infinitely; one level of reflections may show my words in reverse, while the next captures them legibly, but only partially, and still the next circle of reflection reframing my words in the relationships I develop as a human being and researcher; each reflection revealing something I haven't seen, a possibility I haven't considered. Poetry, perhaps more than any other approach or discipline, gets to the essence of qualitative methodology. It presents (and is a catalyst for) a window into the heart of human experience (McCulliss, 2013). Essentially, understanding humanity is the very premise of qualitative research. Utilizing poetry in qualitative research creates a space to unravel parts of humanity and convey the experiences to a larger audience. 


\section{ANALYSIS OF IDENTITIES}

- Conceptualizing reflexivity as a personal reflection or analysis of my subjectivity works best for me because it involves an inward analysis of all that influences my identity.

- Reflexivity opens space for enhancement. By constantly reflecting on what was the most difficult part for me and what I would change for next time, I, as a green researcher, kept overcoming my weaknesses and enhancing myself. Reflexivity is not only at the heart of autoethnography and cultural critique as Berry said, but also at the heart of the studying process for a graduate student.

\section{QUERY}

- "Reflexivity is a way for researchers to account for their personal biases and examine the effects that those biases may have on the data produced" (Hesse-Biber, 2014, p. 3). This definition didn't mean much to me when I first read it. At the time, reflexivity was a relatively new term to me, and I didn't see much of a purpose to it. However, a recent research project made me realize how much of a bias I had before I even began collecting data.

Throughout our reflections, we considered reflexivity as an intentional engagement of relational meanings as they develop and shift in changing contexts. Lindlof and Taylor (2011) explain that by realizing that our work as researchers is always situated in relationships -in relationships with the research literature, with the people we are studying - we are able to get our bearings in a world of diverse, shifting, and often contentious meanings. This connectedness requires the researcher to be open, flexible, and socially conscious. We also consider the "labor of reflexivity" as defined through the mental and physical work that is reflexive thinking (Madison, 2011). This demands that students become transparent and accountable as researchers.

If we adapt Berry's (2013) spinning metaphor about reflexivity, it means that we cannot go back to a space the same as when we arrived; we are always arriving with an altered sense of identity and reality. The consideration of a spinning reflexivity demonstrates the interactive and dynamic process of other and selves in the process of reflexivity. It allows us to consider research from multiple perspectives. Spinning reflexivity creates an opportunity for us to challenge our thought process and make room for alternate ways of interpretation; to move beyond previous knowledge and experiences. 


\section{Note}

1. We thank the other students in MC 6400 for their contributions to reflexivity: Benjamin Brojakowski, Jason Burnett, Linsay Cramer, Alexander Davis, Zhao Ding, Andrew Donofrio, Sabrina Foti-Schwartz, Jing Jiang, Weiwei Jiang, E. Yen Lee, Lingfei Luan, Hedieh Taraghi, Liu Yang, Saleha Azmi, Arthi Chadrasekaran, Matthew Herdershot, Tonya Koenig, and Clitha Mason

\section{References}

Berger, R. (2015). Now I see it, now I don't: Researcher's position and reflexivity in qualitative research. Qualitative Research, 15(2), 219-234. doi:10.1177/1468794112468475

Berry, K. (2013). Spinning autoethnographic reflexivity, cultural critique, and negotiating selves. In S. Holman Jones, T. E. Adams, and C. Ellis (Eds.), Handbook of autoethnography (pp. 209-227). New York: Routledge.

Berry, K., \& Clair, R. P. (2011). Contestation and opportunity in reflexivity: An introduction. Cultural Studies $\Leftrightarrow$ Critical Methodologies, 11(2), 95-97. doi:10.1177/15327086114013392

Calafell, B. M. (2013). (I)dentities: Considering accountability, reflexivity, and intersectionality in the I and the we. Liminalities: A Journal of Performance Studies, 9, 6-13. doi:10.1080/17513057.2016.1120850

Creswell, J. W. (2007). Qualitative inquiry and research design: Choosing among five designs. Thousand Oaks, CA: Sage.

Cutcliffe, J. (2003). Reconsidering reflexivity: Introducing the case for intellectual entrepreneurship. Qualitative Health Research, 13, 136-148. doi:10.1177/1049732302239416

Denzin, N. K., \& Lincoln, Y. S. (2000). Handbook of qualitative research. Thousand Oaks, CA: Sage.
Ellenwood, R. (2005). New life in the exquisite corpse. In M. Bishop \& C. Elson (Eds.), Contemporary French and Francophone art (pp. 205-210). Amsterdam, Netherlands: Rodopi.

Faulkner, S. (2014). Family stories, poetry, and women's work: Knit four, frog one (poems). Rotterdam, Netherlands: Sense Publishers.

Faulkner, S. L. (2016). The art of criteria: Ars criteria as demonstration of vigor in poetic inquiry. Qualitative Inquiry. doi:10.1177/1077800416634739

Fox, A., \& Allana, J. (2014). Doing reflexivity: Moments of unbecoming and becoming. International Journal of Research \& Method in Education, 37(1), 101-112. doi:10.1080/17437 27X.2013.787407

Guillemin, M., \& Gillam, L. (2004). Ethics, reflexivity, and ethically important moments in research. Qualitative Inquiry, 10, 261-280. doi:10.1177/1077800403262360

Hesse-Biber, N. S. (2014). Feminist research practice, a primer (2nd ed.). Thousand Oaks, CA: Sage.

Lietz, C. A., Langer, C. L., \& Furman, R. (2006). Establishing trustworthiness in qualitative research in social work. Qualitative Social Work, 5(4), 441-458.

Lindlof, T. R., \& Taylor, B.C. (2011). Qualitative communication research methods (3rd ed). Thousand Oaks, CA: Sage. 
Madison, D. S. (2011). The labor of reflexivity. Cultural Studies $\leftrightarrow$ Critical Methodologies, 11(2), 129-138. doi:10.1177/1532708611401331

McCulliss, D. (2013). Poetic inquiry and multidisciplinary qualitative research. Journal of Poetry Therapy, 26(2), 83-114. doi:10.1080/08 893675.2013.794536

Ragin, C. C. (1987). The comparative method: Moving beyond qualitative and quantitative strategies. Berkeley, CA: University of California Press.

Tracy, S. J. (2013). Qualitative research methods: Collecting evidence, crafting analysis, communicating impact. Hoboken, NJ: Wiley-Blackwell.
Warren, J. T. (2011). Reflexive teaching: Toward critical autoethnographic practices off/in/on pedagogy. Contestation and opportunity in reflexivity Cultural Studies $\rightarrow$ Critical Methodologies, 11, 130-144. doi:10.1177/15327 08611401332

Watt, D. (2007). On becoming a qualitative researcher: The value of reflexivity. The Qualitative Report, 12(1), 82-101. Retrieved from http://nsuworks.nova.edu/tqr/vol12/ iss $1 / 5 /$

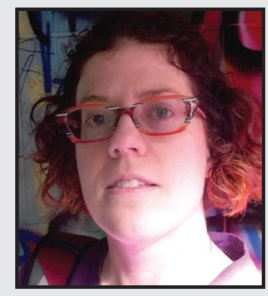

Sandra L. Faulkner is Director of Women's, Gender and Sexuality Studies at Bowling Green State University. Her interests include qualitative methodology, poetic inquiry, and the relationships between culture, identities, and sexualities in close relationships. She has published over 25 articles in journals such as Qualitative Health Research, and Cultural Studies $\leftrightarrow$ Critical Methodologies, and her books Poetry as Method: Reporting Research Through Verse and Inside Relationships: A Creative Casebook on Relational Communication with Routledge. Sense published her poetry memoir, Knit Four, Frog One (2014), and her co-authored book (with Squillante), Writing the Personal: Getting Your Stories Onto the Page (2016). 


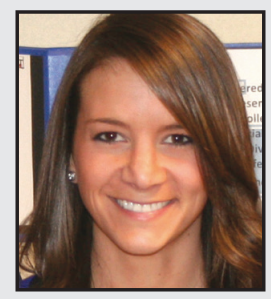

Chelsea A. Kaunert, M.Ed. is a doctoral student and instructor (Sport Administration Department) at Bowling Green State University in the School of Media \& Communication. She is a 2014 graduate of Bowling Green State University where she earned her Master of Education in Sport Administration. She holds a Bachelor of Arts from Muskingum University in Communication and Gender Studies. Her research interests include communication and sport, representations of femininity in sport media, sport media campaigns and constructions of social and cultural identities. Most recently, Chelsea's research is focusing on girl athlete identity construction and social media self-representations of female athletes.

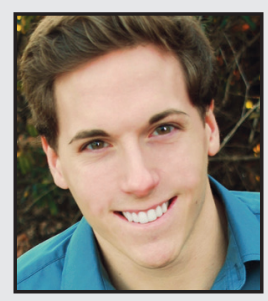

Yannick Kluch is a doctoral student in the School of Media and Communication at Bowling Green State University. His research interests include critical and cultural studies, men and masculinities, and identity construction in and through sport. Yannick is also interested in examining the potential of sport to be used as a vehicle for social change. He has presented his research at various national and international conferences, including the annual convention of the National Communication Association, the Global Communication Association Conference, and the International Conference on Sport and Society. His research has been published in Interactions: Studies in Communication \& Culture. 


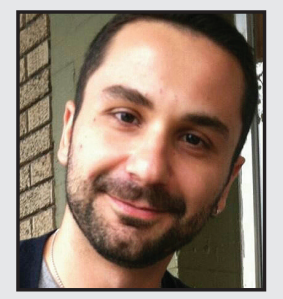

Essen Saygin Koc is a doctoral student in Media and Communication at Bowling Green State University. He holds a Master's degree in Applied Communication Theory and Methodology from Cleveland State University, and a Bachelor's degree in International Relations from Istanbul Bilgi University. In his doctoral studies, he focuses on intercultural communication and identity, employing (auto)ethnographic approaches. In addition, he has presented work on race, gender, popular culture, and media at national and regional conferences.

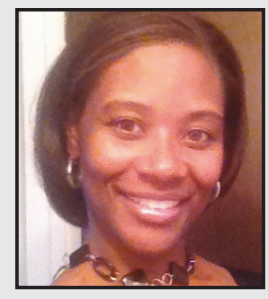

Stormy P. Trotter is a doctoral student in Media and Communication at Bowling Green State University also working toward a Graduate Certificate in Women Studies. She received her M.A. in Arts Administration with a concentration in Communication at Eastern Michigan University. Her research interests include communication and trauma with an emphasis on Post-Traumatic Stress Disorder, communication and identity, arts-based methods, and media representation. She has co-authored multiple entries in the International Encyclopedia of Communication Research Methods, provided editorial support for a special issue of the Journal of Family Communication, worked on collaborative research teams, and presented at various research symposiums. 